\title{
Armani dice no a las pieles
}

Keywords: Animal de peletería, pieles de animales, moda, etiquetaje, "cruelty free", "fur free", Armani, Stella McCartney, Derecho Animal.

\section{El 22 de marzo 2016 el diario italiano "La Repubblica"}

( http://www.repubblica.it/ambiente/2016/03/22/news/armani_rinuncia_alle_pellicce-136081880/), se hacía eco de una noticia muy importante para el mundo de la moda. El diseñador Giorgio Armani, que ha marcado con su influjo la segunda mitad del S. XX, de modo que la gran Suzy Menkes, editora internacional de VOGUE (http://www.vogue.es/suzy-menkes/articulos/giorgio-armani-plays-in-the-sandsuzy-menkes/20836), ha denominado a esta etapa la "era Armani", declaraba que, a partir de la colección de otoño invierno 2016-17, no usará en sus diseños pieles de animales, en consideración a que hoy en día, gracias al progreso tecnológico, se pueden encontrar alternativas válidas que no comporten prácticas crueles con los animales ${ }^{1}$

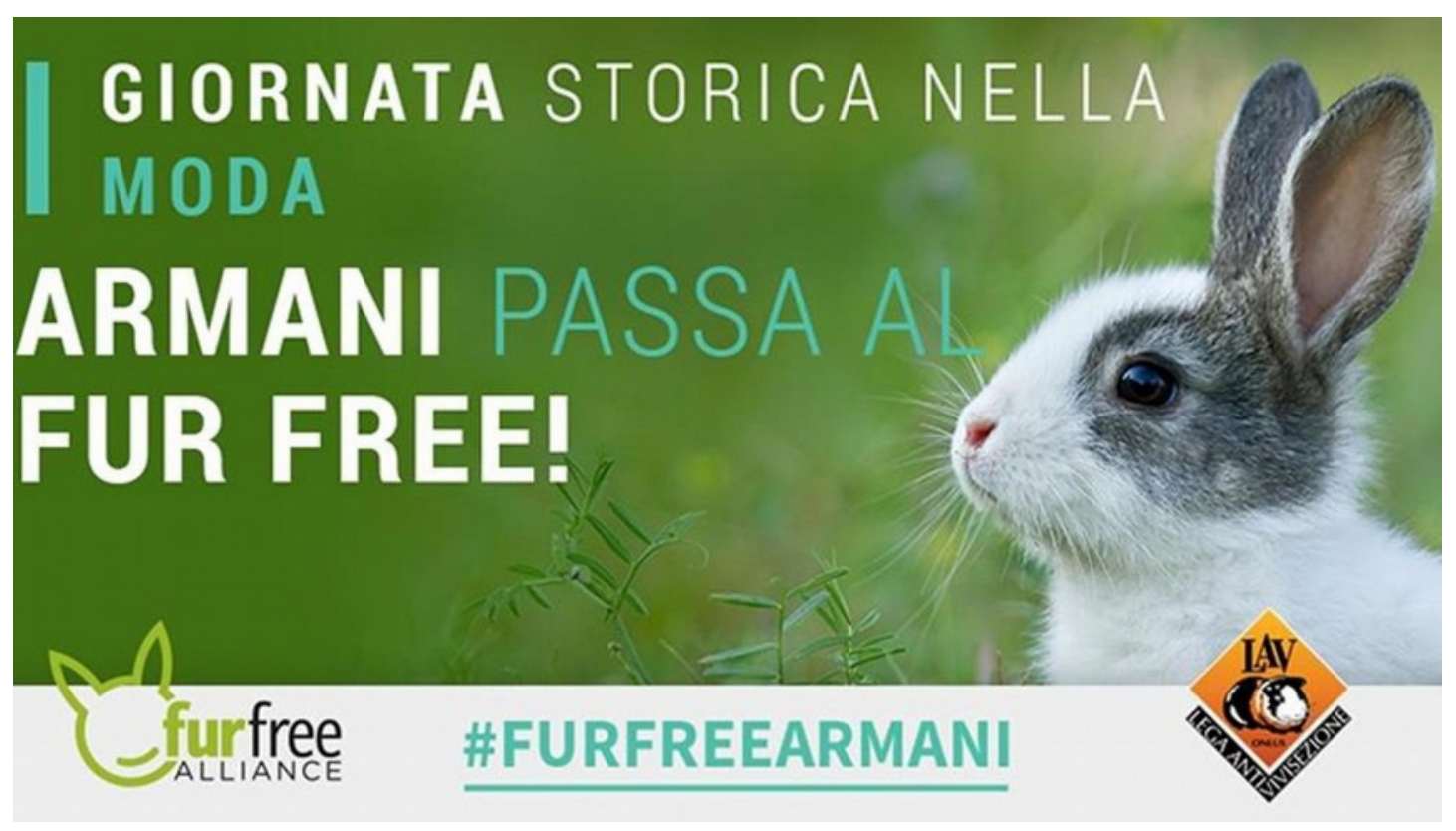

La declaración del reconocido diseñador italiano, realizada de acuerdo con la "Fur Free Alliance" (http://www.furfreealliance.com/), ha producido oleadas de simpatía entre los animalistas, pero, sobre todo, ha removido a las grandes casa de moda, a los periodistas y revistas especializadas, bloggers de

1 La declaración de Giorgio Armani, vale la pena de ser leída en su integridad: "Il progresso tecnologico raggiunto in questi anni - ha dichiarato Giorgio Armani - ci permette di avere a disposizione valide alternative che rendono inutile il ricorso a pratiche crudeli nei confronti degli animali. Proseguendo il processo virtuoso intrapreso da tempo, la mia azienda compie quindi oggi un passo importante a testimonianza della particolare attenzione verso le delicate problematiche relative alla salvaguardia e al rispetto dell'ambiente e del mondo animale". Un firme alegato en favor del respeto al medio ambiente y al trato ético con los animales. 
moda, estilistas y, en definitiva, a una industria que representa un alto porcentaje de ganancias (Armani es la segunda industria italiana, por detrás de "Ferrero"), de decisiva influencia en el mundo y que usa aproximadamente 95 millones de animales para servirse de sus pieles, aparte, claro está de la industria cosmética que, a pesar de las prohibiciones ${ }^{2}$, sigue testando con animales, como es el caso de L'Oreal y otras marcas.

Desde que hace algunos años Stella McCartney (http://www.thesartorialist.com/paris/stella-mccartneyintroduces-fur-free-fur/), declarara que en sus diseños no se usarían materiales que procedieran de la crueldad contra los animales, las creaciones de la diseñadora británica lucen orgullosamente la etiqueta "Fur Free", que es una exigencia ética que orienta a los consumidores aunque no haya por el momento ninguna regulación al respecto. La cuestión del etiquetaje ético y sostenible, a diferencia de otros ámbitos del consumo (alimentos, cosmética, limpieza, por ejemplo), aún está por hacer en la industria de la moda ${ }^{3}$.

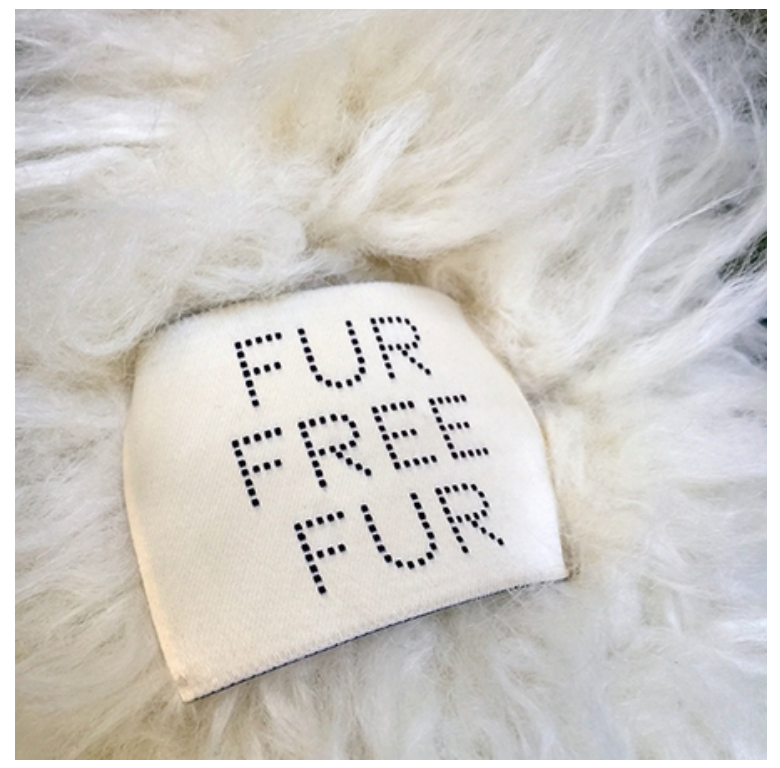

También otros diseñadores como Calvin Klein, Tommy Hilfiger, Hugo Boss, así como grupos de moda low-cost (Zara, H\&M, American Apparel, Berschka, Asos), se han posicionado a favor de la moda ecológica, contraria al empleo de animales para sus creaciones. Desde que la famosa diseñadora -hija del no menos famoso músico Sir Paul McCartney, también activista por los animales-, se definiera en favor del uso de alternativas éticas, no ha habido vuelta atrás. En Italia, la Lega Antivivisezione (Lav http://www.lav.it/), ha promovido el proyecto Animal Free Fashion (http://www.animalfree.info/) que anima a vestir moda libre de crueldad animal ("Cruelty free") y brinda alternativas para una moda respetuosa y sostenible.

Como ha ocurrido con otros movimientos sociales que han influido decisivamente en la actividad económica, es seguro que la transformación de la industria peletera se hará realidad o desaparecerá. No

2 A propósito del RD 53/2013 de 1 de febrero, en aplicación de la Directiva 2013/15/CE, Vid. GIMÉNEZ-CANDELA, M., Cosmética y experimentación en animales (http://www.derechoanimal.info/esp/page/2464/cosmetica-y-experimentacion-enanimales), con la normativa y la literatura relativa allí citada.

3 De gran interés, el artículo de SOUTHERN, C.E., Human v. House: a Combat for Couture Command of Luxury Labels, en DePaul Journal of Art, Technology \& Intellectual Property Law (24) 2013, Issue 1, 49ss. 
creo que, a día de hoy, haya alguien que use un corsé de ballenas, porque la mítica prenda se realiza actualmente con materiales sintéticos, que han sustituido con ventaja al uso de las láminas o "barbas de ballena". Un conocido mío, durante los años de internado en un colegio de los Jesuitas -por cierto en Orihuela-, contaba que los internos coleccionaban en una caja los "objetos" que encontraban entre la comida que les servían. La "estrella" de dicha caja era precisamente una ballena de corsé, se supone que de una de las cocineras.

La moda es cualquier cosa menos algo banal. Es arte y un reflejo de la sociedad, de su realidad, de sus carencias y también de sus sueños e ideales. Es un véctor del cambio social, así que hay que celebrar que llegue a un sector tan influyente el deseo de respetar a los animales y de cuidar del medio ambiente. Me gustaría saber que en adelante en las Escuelas de Diseño y en los Máster de moda -que los hay!-, se enseña una variante de la responsabilidad social corporativa de las empresas, como es el trato ético con los animales. Me alegrará mucho saber que, tras Armani, los grandes Maestros, las grandes "Maison" del diseño, se posicionan en favor de alternativas respetuosas con quienes lo que quieren es seguir vistiendo su piel, con la que han nacido. 